\title{
PENSAMENTO COMO SUSPENSÃO DO MUNDO: aproximações entre Arendt e Herbart para (re)pensar a ação pedagógica \\ Jenerton Arlan Scbütz. \\ Odair Neitzel
}

Resumo

À luz do pensamento de Hannah Arendt e Johann Herbart, o texto propõe refletir sobre a relação entre o pensar e o mundo comum. Afinal, o que nos faz pensar? Para dar conta de responder tal indagação, iniciaremos a discussão em torno da relação entre entendimento (Verstand) e razão (Vernunft) que Hannah Arendt faz com base em Kant; por conseguinte, faremos uma releitura da concepção de disciplina formativa ou aconselhamento de Herbart, isso, com o intuito de aferir que sujeito é levado a pensar a partir do momento em que toma a si e o mundo em reflexão (suspendendo-o); por fim, apresentamos as três figuras socráticas, que, para Arendt, fomentam a suspensão do mundo e colocam o sujeito em movimento reflexivo, sob a atividade do pensamento. Ademais, esse movimento permite (re)pensar a ação pedagógica fundada na atividade do pensamento e na continuidade, durabilidade e aperfeiçoamento do mundo humano comum, é isso que só a educação e o professor podem e devem fazer.

Palavras-chave: mundo humano comum; pensar; docência.

THINKING AS A SUSPENSION OF THE WORLD: Arendt and Herbart approaches to (re)think pedagogical action

Abstract

In the light of the thinking of Hannah Arendt and Johann Herbart, the text proposes to reflect on the relationship between thinking and the common world. After all, what makes us think? To answer this question, we will begin the discussion about the relationship between understanding (Verstand) and reason (Vernunft) that Hannah Arendt makes based on Kant; therefore, we will reread Herbart's conception of formative discipline or counseling, in order to assess which subject is led to think from the moment he takes himself and the world in reflection (suspending it); Finally, we present the three Socratic figures, which, for Arendt, foster the suspension of the world and place the subject in reflexive movement, under the activity of thought. Moreover, this movement allows (re) to think the pedagogical action based on the activity of thought and the continuity, durability and improvement of the common human world, this is what only education and the teacher can and should do.

Keywords: common human world; think; teaching.

\section{PENSANDO COMO UNA SUSPENSIÓN DEL MUNDO:} enfoques entre Arendt y Herbart para (re)pensar la acción pedagógica

Resumen

A la luz del pensamiento de Hannah Arendt y Johann Herbart, el texto propone reflexionar sobre la relación entre el pensamiento y el mundo ordinario. Después de todo, ¿qué nos hace pensar? Para responder a esta pregunta, comenzaremos la discusión sobre la relación entre comprensión (Verstand) y razón (Vernunft) que Hannah Arendt establece en base a Kant; por lo tanto, volveremos a leer la concepción de Herbart de la disciplina formativa o el asesoramiento, para evaluar qué tema es llevado a pensar desde el momento en que se toma a sí mismo y al mundo en reflexión (suspendiéndolo); Finalmente, presentamos las tres figuras socráticas que, para Arendt, fomentan la suspensión del mundo y colocan al sujeto en movimiento reflexivo, bajo la actividad del pensamiento. Además, este movimiento permite (re) pensar la acción pedagógica basada en la actividad del pensamiento y la continuidad, durabilidad y mejora del mundo humano común, esto es lo que solo la educación y el maestro pueden y deben hacer.

Palabras clave: mundo humano común; pensar; enseñanza. 


\section{INTRODUÇÃO}

Para Herbart não há ação pedagógica que não ensine e eduque em simultâneo. Assevera que "[...] não concebo educação sem ensino, assim como [...] não concebo um ensino que não eduque" (HERBART, 2010, p. 16). Reservadas as diferenças, Herbart encontra ressonância em Arendt (1996, p. 276), quando esta afirma que "[...] não se pode educar sem ao mesmo tempo ensinar; uma educação sem aprendizagem é vazia e se degenera facilmente em patética retórica moral. E pode-se muito bem ensinar sem educar, podendo aprender até a mais avançada idade, sem com isso se tornar educado".

As duas afirmações são muito próximas, apesar da distância que separa os dois pensadores no tempo. Em todo caso as semelhanças são dignas de consideração. Elas se somam em vários aspectos, como no caso da perspectiva epistemológica assumida, até as reflexões teóricas e filosóficas dos dois pensadores. Não sendo possível tratar essas diferenças e proximidades, nos concentraremos em um aspecto que nos parece relevante nos dois pensadores e que pode ser traduzido na seguinte pergunta: o que nos faz pensar? Para tanto, faremos primeiramente uma aproximação ao pensamento de Arendt, da distinção que faz entre entendimento (Verstand) e razão (Vernunft) com base em Kant (2001), concentrando-nos naquilo que a pensadora concebe como pensamento e sobre o que nos faz pensar.

A partir disso, faremos uma releitura da concepção de disciplina formativa ou aconselhamento de Herbart (2010). Buscaremos sinalizar que tanto em Arendt (1996) como em Herbart (2010), o sujeito é levado a pensar a partir de um momento de negação do habitual, tomando-se a si e o mundo em reflexão. O papel do mestre como interlocutor no diálogo, é do sujeito que faz pensar pela descontinuidade do que é usual, do que é fluido, constante e instaura o sujeito a um certo estado e inércia.

Para tanto, daremos destaque à análise que Arendt (1996) faz de três imagens ou figuras socráticas que, para a autora, fomentam a suspensão do mundo e colocam o sujeito em movimento reflexivo, sob a atividade do pensamento. Em Herbart (2010) encontramos a reflexão que permite situar mais precisamente essa atividade no processo educativo, sob o conceito de Zucht ou disciplina formativa, que passa pelo papel do mestre que aconselha (Beratet) seu aprendiz.

\section{O QUE NOS FAZ PENSAR?}

Hannah Arendt inicia sua jornada na obra $A$ vida do espirito (2014), buscando responder à pergunta sobre o que nos faz pensar. Para tanto, primeiramente, ela se ocupa em definir o que seja essa atividade espiritual. E nesse sentido, Arendt (2014) se desvia do que é quase um lugar-comum da filosofia, ao conceber o mundo espiritual como extensão transcendente do mundo das aparências. Contudo, não se trata tanto de negar a existência de uma esfera transcendente e de outra real. Mas muito mais em inverter essa hierarquização. E que a verdade sempre está no Ser e o mundo real ou das aparências é uma mera imitação impeditiva do mundo verdadeiro que jaz por trás das aparências.

Hannah Arendt (2014, p. 39) se debruça sobre essa relação entre ser e aparecer, analogia própria da metafísica tradicional. Nessa perspectiva, o homem pensante “[...] deve deixar o mundo das aparências entre as quais ele natural e originalmente se encontra em casa" e se mover em direção ao mundo verdadeiro do ser, eterno e imutável que se encontra fora deste mundo. O fato é que para Arendt (2014), o mundo das aparências sempre é o lugar primeiro de qualquer ser humano, ponto de partida para qualquer jornada ou atividade espiritual, levando a autora a defender o mundo fenomênico como mais que simples aparência. A retirada espiritual do mundo então é 
sempre uma busca por aquilo que está subjacente a esse mundo composto de coisas que aparecem. A crítica, nesse caso, se dirige ao fato de que a tradição filosófica toma essa esfera de pressupostos que se esconde atrás do véu da realidade como mais elevada e importante (ARENDT, 2014), ao mesmo tempo como negação do mundo que é a casa humana. Tanto o filósofo quanto o cientista estão sujeitos à primazia da aparência, e seus esforços conceituais buscam encontrar o que está além das meras aparências, pôr a nu o que por si só não apareceria. Porém, somos sempre contingenciados por esse mundo fenomênico.

A nosso ver, o que é importante perceber aqui é que não se trata tanto de negar uma dimensão espiritual do saber, nem a prerrogativa exclusiva de acesso à verdade por alguns seres humanos especiais, mas de exigir a suspensão do mundo das aparências como condição de acesso à verdade e ao Ser. Não é possível em Arendt (2014) negar esse mundo, o mundo comum, uma vez que não haverá pensamento, nem sequer conhecimento, sem que seja através do mundo das aparências. Somos o mundo das aparências e nos constituímos nele, de tal modo que negar esse mundo seria negar o próprio sujeito, uma vez que apenas os humanos possuem mundo.

Dito isso, é interessante levar em consideração o processo de perceber e ser percebido, conhecer e operar espiritualmente sobre o mundo a partir da distinção conceitual de corpo, alma e espírito. O corpo percebe, a alma conhece, e o espírito ou pensamento concebe o sentido para o mundo. O que o corpo percebe e a alma conhece o nosso espírito traduz em significados. A atividade do pensamento é invisível e não aparece ao mundo enquanto tal, pois toda sua tentativa de aparecer no mundo é sempre opaca e imprecisa. Isso significa que toda expressão do pensamento é sempre uma atividade metafórica, uma tentativa de tradução discursiva dos estados internos. Essa atividade do espírito, portanto, constitui uma atividade muda, e segundo Hannah Arendt (2014, p. 48) essa atividade que não aparece em sua integridade "[...] constitui uma espécie de discurso, um diálogo silencioso de mim comigo mesmo". Portanto, só aparece aos outros através de um processo de tradução metafórico dos sentidos e significados a partir desta autoobservação. Ainda, o meu eu é algo exclusivo do próprio sujeito a que somente eu tenho acesso.

As atividades espirituais são sempre concebidas em palavras antes mesmo de serem comunicadas. Para tanto faz-se uso do discurso. Não há pensamento sem discurso e vice-versa. Segundo Arendt (2014, p. 49), o pensamento não é uma atividade própria de algum órgão do corpo, apesar de dar a impressão de ser localizado no cérebro e, portanto, mais preciso que as atividades da alma, como as emoções. Como tradução conceitual dos estados da alma, o espírito visa conectar "[...] a lacuna entre o mundo dado à experiência sensorial e um domínio onde tais apreensões imediatas de evidência não podem existir" (ARENDT, 2014, p. 49). Em relação a isso, Hannah Arendt (2014, p. 49) se expressa da seguinte forma: “[...] a linguagem da alma em seu estágio meramente expressivo, não é metafórica; ela não se afasta dos sentidos, nem usa analogias quando fala em termos de sensações físicas".

Essas distinções aproximam-nos da compreensão do que seja a atividade do pensamento. Importa destacar, porém, que a alma não pode ser reduzida às atividades funcionais do corpo e é através dela que é permitido que nos sintamos vivos e, portanto, percebamos nossa singularidade. Sem esses estados da alma estaríamos reduzidos a uma existência meramente instintiva. Porém, a percepção dessa singularidade, que se constitui nesses complexos estados da alma, depende ainda que o pensamento e a atividade espiritual se traduzam discursivamente e se construam em um significado sobre si mesmo.

Com isso, Arendt (2014) confronta diretamente a tradição do pensamento filosófico em que o espírito ou pensamento são contrapostos ao corpo e tomando espírito e alma praticamente como sinônimos. Para a autora, porém, o espírito se distingue do corpo e da alma, por ser uma atividade que se desprende, e nesse sentido transcende a uma existência funcional, material ou 
biológica. A autora poderia embasar críticas a muitas afirmações ligadas às descobertas da neurociência e da neurofilosofia. Talvez Damásio (2011) seja um dos pensadores que percebeu algo diferente em relação ao que possa ser entendido como consciência — salvo as distinções em relação ao conceito de espírito em Arendt. Deveras, afirma a pensadora que "[...] por princípio, o pensamento fundamental não tem fundo. Ele é, se se quiser, um abismo" (ARENDT, 2014, p. 51). Já a alma não é desprovida de fundo e transborda do corpo.

A partir da apresentação desses conceitos, é preciso que nos ocupemos com outro conceito fundamental ao pensamento de Arendt $(2014$, p. 66) se desejamos responder o que é que nos faz pensar: o conceito de senso comum ou de realidade (realness). O sentido de realidade, uma espécie de sexto sentido humano, que não é produzido por um dos nossos sentidos, mas é o meio pelo qual se mantêm reunidos os cinco sentidos, assim garantindo a coerência entre o que a percepção diz a respeito de um objeto. O senso comum (sensus communis) não é localizado em um órgão do corpo. Mas é o sentido responsável por adequar as sensações dos cinco sentidos. Importa destacar que o senso comum resulta da relação intersubjetiva com a qual posso averiguar a correspondência entre minha percepção da aparência de algo no mundo, com a de outros iguais a mim. O senso comum é "[...] um sentimento de realidade imediatamente compartilhado, que ajusta nossos sentidos privados a um mundo comum" (NETO, 2009, p. 16). Ou seja, a "[...] subjetividade do parece-me é mediada pelo fato de que o mesmo objeto também aparece para os outros, ainda que seu modo de aparecer possa ser diferente" (ARENDT, 2014, p. 67). Trata-se do sentido, que não é bem uma sensação.

Segundo Arendt (2014), esse sentido interno geralmente é confundido com a faculdade de pensar. A razão principal estaria na propriedade invisível própria do pensamento e do senso comum. $\mathrm{O}$ argumento de que a atividade de pensar não pode ser condicionada nem pelas exigências da vida, nem pelos imperativos do mundo, sinaliza que ninguém pode se manter inteiramente fora da Vita Activa que faz de cada homem um ser-do-mundo; ninguém pode permanecer indefinidamente engajado na vida do espírito, que faz de cada homem um ser pensante. $O$ pensamento não pode dissolver o sentido de realidade ou do bom senso (le bon sens) (ARENDT, 2014, p. 70).

Apesar disso, fica evidente que o que torna o homem um ser especial, distinto de outras espécies, é sua capacidade de pensar, de retirar-se espiritualmente do mundo, mesmo que não possa deixá-lo ou transcendê-lo. Como pensante é um ser-do-mundo que pode recuar espiritualmente das suas condições mundanas e existências. A atividade espiritual do pensamento invisível se dá dentro do mundo das aparências e é realizado por um ser que aparece. A pergunta então que Arendt (2014) faz é: como e onde localizar o espírito em suas atividades invisíveis em um mundo de aparências? Possui ele o/um lugar adequado neste mundo?

Arendt (2014) considera que, embora o conhecer e o pensar tenham um vínculo, é importante distinguir uma atividade da outra. A preocupação de Arendt (2014) em estabelecer essa distinção está relacionada à sua análise sobre o mundo moderno, no qual o pensar não instrumental é cada vez menos valorizado e presente. Contrário a isso, o conhecimento, a ciência moderna e as tecnologias ganharam um status mais importante. Aí está o problema, conforme Arendt (2010), quando se passa a aplicar os critérios próprios do conhecimento indistintamente também ao pensar, de modo que se corre o perigo de perder de vista a importância peculiar dessa atividade do espírito. Menospreza-se o pensar, de tal modo que pensamento e busca de sentido não podem satisfazer as exigências do conhecimento, seja ele do âmbito do senso comum ou do âmbito das ciências.

O aviso de Arendt, segundo Almeida (2011), se não quisermos banir uma dimensão fundamental de nossa existência, indica a necessidade de atentar para o pensar em sua especificidade, ou seja, enquanto atividade do espírito distinta do conhecer e regida por critérios e 
objetivos próprios. Com o intuito de compreender a peculiaridade de cada uma das atividades do espírito, Arendt (2014) recorre à distinção entre o intelecto e a razão, respectivamente, Verstand e Vernunft.

Com isso, já é possível tocar na leitura arendtiana da filosofia de Kant (2001) e da distinção entre intelecto (Verstand) e razão (Vermunft). Segundo a pensadora, isso estaria ligado a uma descoberta escandalosa da razão como capaz de se ocupar com conhecimento não verificável. Ou seja, de que o homem não pode ser limitado em seu pensamento ou impedido de especular sobre temas como deus, liberdade e imortalidade. Hannah Arendt (2014) vislumbra nisso uma extraordinária contribuição de Kant (2001): a distinção entre atividade de pensar e conhecer. Enquanto o pensamento se interessa pelo significado, o conhecimento se conduz para a cognição. A autora afirma que talvez o próprio Kant não tenha percebido sua descoberta e a importância dela e, por razões concernentes à própria investigação de Kant, o potencial que o filósofo liberara para a razão pensar, foi definido por ele como espaço para a fé.

Segundo Arendt (2014, p. 30):

Mas, se é verdade que o pensamento e a razão têm justificativa para transcender os limites da comunicação e do intelecto - e Kant fundou essa justificativa na afirmação de que os assuntos com que lidam, embora incognoscíveis, são do maior interesse existencial para o homem -, então o pressuposto deve ser: o pensamento e a razão não se ocupam daquilo de que se ocupa o intelecto. Para antecipar e resumir: a necessidade da Razão não é inspirada pela busca da verdade, mas pela busca do significado. E verdade e significado não são a mesma coisa.

A faculdade de pensar ou Vernunft (razão) que fora distinguida por Kant (2001) de Verstand (intelecto) é inteiramente diferente na concepção de Arendt. Ou seja, “[...] o intelecto (Verstand) deseja aprender o que é dado aos sentidos, o pensamento (Vernunft) quer compreender seu significado" (ARENDT, 2014, p. 75). O pensamento não busca a verdade, mas o sentido. Ademais, pode-se considerar que o pensar não produz nenhum resultado concreto em si, mas refere-se ao sentido que buscamos sempre naquilo que nos acontece. Para tanto, Arendt (2014) chama atenção para o termo latino perceptivo e que Kant tomara em alemão como $W$ abrnebmung que, por sua vez, significa tomar aquilo que é dado à percepção como verdadeiro ( $W a h r)$.

Para Arendt (2014, p. 188), os profissionais da filosofia quando perguntados sobre o que lhe faz pensar, acreditam que essa atividade "[...] não surge das suas próprias experiências enquanto está pensando". E as respostas dadas por estes são sempre muito vagas e distantes para encontrar um sentido na vida cotidiana. Mas é nesse espaço mundano que acontece o pensamento, de modo constante, "[...] interrompendo os processos comuns da vida — do mesmo modo que a vida cotidiana constantemente interrompe o pensamento" (ARENDT, 2014, p. 188).

O ego pensante não tem qualquer impulso para aparecer no mundo por si mesmo. "Ele é um personagem escorregadio, invisível não apenas para os outros, mas também para o próprio eu, impalpável e impossível de ser aprendido" (ARENDT, 2014, p. 188). A questão, então, é como é possível, a partir do mundo das aparências, "[...] trazê-lo à luz do dia, como provocá-lo, por assim dizer, a manifestar-se?” (ARENDT, 2014, p. 189). A autora afirma que, para tal resposta, é preciso procurar um pensador que unifique em sua pessoa, “[...] duas paixões aparentemente contraditórias, a de pensar e a de agir" (ARENDT, 2014, p. 189). Essa união em uma pessoa tem a finalidade de “[...] estar à vontade nas duas esferas e ser capaz de passar de uma à outra aparentemente com a maior facilidade, do mesmo modo como nós avançamos e recuamos constantemente entre o mundo das aparências e a necessidade de refletir sobre ele" (ARENDT, 2014, p. 189). 
Não obstante, somos aquilo que os homens sempre foram, seres pensantes. Sentimos a necessidade de entender e compreender o mundo e de refletir sobre o nosso lugar nele. Contudo, torna-se necessário compreender a distinção que Arendt (2014) faz das três faculdades do espírito: o pensar, o querer e o julgar. Para a autora, o pensar sempre traz para o espírito as coisas ausentes no tempo e no espaço para que possamos, a partir disso, refletir sobre elas. Ademais, é por isso que o pensar exige o distanciamento do mundo para buscar a compreensão de nossa experiência nele. Lembramos do que acontece e perguntamos sobre o sentido disso tudo (ARENDT, 2014).

A faculdade do querer diferencia-se do pensar que volta o seu olhar para o passado, e volta o seu olhar para o futuro. O querer trata dos projetos e das projeções e está dividido pelo conflito entre as diferentes vontades que surgem, porém precisa decidir-se sobre elas. Pode-se aferir, ainda, que o querer está ligado à possibilidade que temos de iniciar algo novo - imprevisível - e, portanto, visa realizar os projetos no mundo mesmo que, enquanto faculdade do espírito, não ocorra neste mundo (ARENDT, 2014).

Por fim, o julgar refere-se à capacidade de distinguir entre o belo e o feio, entre o certo e o errado. Analogamente à atividade do querer, essa atividade está mais próxima do mundo do que a atividade do pensar, uma vez que trata de casos específicos e particulares que exigem de nós um posicionamento. A faculdade do julgamento não se orienta (ao menos não deveria) por aquilo que agrada apenas o individual, mas requer o distanciamento dos interesses particulares e a capacidade de imaginar e considerar a opinião do outro. Essa faculdade, portanto, exige a nossa inserção na comunidade, é a faculdade mais política, pelo fato de procurar uma visão isenta de interesses privados e particulares, com a qual, em princípio, todos poderiam concordar.

Portanto, enquanto o pensar exige o distanciamento, o querer e o julgar precisam da aproximação dos acontecimentos que presenciamos e que pedem o discernimento e a ação. Contudo, as atividades do espírito não são separadas umas das outras, outrossim, cada uma possui seus critérios e interesses específicos, além de um modo próprio de operar. Por isso, é importante destacar que nenhuma das três atividades é simplesmente instrumento ou complemento de outra atividade, elas são autônomas.

A condição que esta aprendizagem pressupõe é o pensamento, uma vez que só no pensamento pode ter lugar o diálogo do dois-num-só. Nesse sentido, para pensar é preciso que nos distanciemos temporariamente da presença dos outros para permanecer, por algum tempo, na presença de nós mesmos. Essa retirada do mundo das aparências é "[...] a única condição anterior essencial para o pensamento" (ARENDT, 2014, p. 61), contudo, tal retirada do mundo jamais tem a pretensão de deixá-lo ou transcendê-lo, pois esse "eu" que exige respostas não deixa de fazer parte de uma pluralidade de seres humanos, ou seja, não existe por si só, mas pertence ao mundo.

Em A condição bumana, Arendt (2010, p. 86) questiona o aspecto de isolamento do pensamento e o distanciamento do mundo das aparências:

Mesmo quando o filósofo decide, como Platão, deixar a "caverna" dos negócios humanos, não precisa esconder-se de si mesmo; pelo contrário, sob a luz forte das ideias não apenas encontra a verdadeira essência de tudo quanto existe, mas também encontra-se a si próprio no diálogo entre "eu e eu mesmo" (eme emauto), no qual Platão aparentemente via a essência do pensamento. Estar em solidão significa estar consigo mesmo; e, portanto, o ato de pensar, embora possa ser a mais solitária das atividades, nunca é realizado inteiramente sem um parceiro e sem companhia.

Por isso, podemos considerar que nos distanciamos do mundo para buscar compreender nossa experiência nele. Logo: 
[...] o pensamento é um estar-só, mas não é solidão (loneliness); o estar só é a situação em que me faço companhia. A solidão ocorre quando estou sozinho, mas incapaz de dividir-me no dois-em-um, incapaz de fazer-me companhia, quando, como Jaspers dizia, "eu falto a mim mesmo" (ich bleib mir aus), ou, em outras palavras, quando sou um e sem companhia (ARENDT, 2014, p. 139).

Ademais, o pensar se apresenta como prioritário, uma vez que é o pensamento que, acima de tudo, precisa trazer para o espírito os objetos com os quais o querer e o julgar vão se preocupar. $\mathrm{Na}$ perspectiva da ação, o pensamento sustenta o querer e o julgar, diretamente relacionados na nossa inserção no mundo comum. O pensar, porém, não é só isso, ele possui um fim em si mesmo, a saber, o de compreender o significado dos acontecimentos que nos ocorrem. E, desse modo, o olhar de Arendt recai sobre Sócrates, considerado pela autora como um modelo de pensador pelo fato de não desejar transmitir respostas prontas (fechadas), mas procurando compreender o mundo e querendo fazer com que os outros pensem.

\section{A DISCIPLINA FORMATIVA COMO ABERTURA A SI MESMO EM HERBART}

Se a filosofia puder ser caracterizada como a postura reflexiva e pensante, Herbart (17761841) a situa de modo acertado no fenômeno educacional. Para o pensador, filosofar é uma das atividades mais nobres que um ser humano pode realizar, mas nem por isso é uma atividade que não exige um certo grau de entrega e um redobrar-se sobre si mesmo como caminho de conversão ao próprio sujeito. Herbart (1976) fora seduzido muito jovem ainda pela filosofia e tinha clareza de sua importância para a ação pedagógica. Provavelmente esta é a razão pela qual afirmava que em poucos lugares a filosofia se faz tão necessária quanto no espaço educacional. É nesse espaço do fluxo constante e diário de ideias, ações, problemas, deliberações que a filosofia tem lugar de extrema importância (HERBART, 1976, p. 387).

Se devemos exigir de todo ser humano que pense, que se desenvolva essa atividade obscura que se esconde por trás do sujeito e de sua aparência por meio de uma suspensão temporária do mundo aparente. Então, se torna importante saber como a educação pode provocar esse processo reflexivo, pelo qual o sujeito se redobra sobre si mesmo, em que suspende o influxo mundano sobre o espírito e se toma em reflexão.

Acreditamos que em Herbart (1976) encontramos algumas pistas que podem fomentar a compreensão do movimento de reflexão entre os sujeitos. Trata-se do que em Herbart (1976) conhecemos por instrução educativa (Eržiende Unterricht). Na Introdução de sua Pedagogia Geral, Herbart (2010) afirma desconhecer ensino que não eduque e educação que não ensine. Com essa afirmação, o autor sinaliza para o condicionamento que há entre educar moralmente um sujeito ao processo de conhecimento ou ensino. Ao mesmo tempo que educar é ensino, não é possível educar sem ensinar.

Para dar conta dessa questão, Herbart (1976) concebe o caráter constituído em duas esferas, denominadas por ele de caráter objetivo e subjetivo. Para alguns intérpretes como Benner (1997), essa distinção tem clara inspiração kantiana, da distinção entre estrutura do entendimento e razão pura. Basicamente o caráter objetivo é a estrutura psíquica que o sujeito constitui no processo de vivências e aprendizados. Ou seja, é o que o sujeito subjetiva em sua aparência no mundo, no processo de aparecer diante dos outros e, de outro lado, das representações que constitui, a partir da percepção do mundo que lhe aparece. É o que Herbart (1976) denomina de círculo de pensamento ou Gedangenkreis. Esse conceito se torna central na pedagogia herbartiana, pois é sobre ela que se constitui a fortaleza do caráter moral. A Gedangenkreis não é ainda capacidade de 
moralidade, mas é a base sob a qual se fortalece o aspecto moral de cada sujeito. Sendo a base, ele condicionará os limites e os alcances da capacidade de moralidade do sujeito.

Disso podemos reter dois pressupostos: (1) o horizonte de desenvolvimento da vontade do aprendiz é proporcional àquilo que este tenha vivenciado, aprendido e assimilado; (2) o caráter jamais pode ser dado antes do círculo de pensamento que se constitui a partir da ação do aprendiz. Não significa, porém, que a formação do caráter possa ser reduzida a uma atividade pragmática ou espontânea. O círculo de pensamentos (Gedankenkreis) é a condição de desenvolvimento da moralidade dada pela instrução nas coisas mundanas e nas coisas próprias do ser humano. A isso se soma a consideração de que não são processos que se desenvolvem em sucessão, mas simultaneamente. Aprender é tornar-se moral e tornar-se moral é aprender.

Importante ter claro que tanto o círculo de pensamentos, quanto a capacidade de moralidade, são esferas em constante processo de desenvolvimento, constituído de uma parte mais sólida, estabilizada, mas também de dimensões maleáveis. Em caso de ser meramente maleável, este sujeito poderia ser um lunático; caso fosse totalmente estável seria um sujeito com pouca capacidade reflexiva e deliberativa. Por esta razão precisa estar em constante processo de ir ao mundo e retirar-se dele, dirigir o olhar ao mundo, mas também em momentos de suspensão voltar o olhar para dentro de si e, assim, realizar um processo de conversão para si mesmo. Essa dimensão flexível e maleável, é o que Herbart (2010, p. 162) entende por “[...] partes maleáveis do carácter". $\mathrm{E}$ isso parece ser vital para a capacidade moral do sujeito, pois a partir daí o caráter mantém certa maleabilidade, podendo se afastar do que lhe é habitual ou da obediência cega na ação e, destarte, buscar reconstruir as razões a partir do próprio entendimento.

O círculo de pensamentos se constitui partindo da participação do sujeito no mundo das aparências, pela ação em experiências e vivências, sendo enriquecido pelo processo instrutivo. Porém, o caráter e a capacidade de deliberação moral não resultam diretamente desse processo. A experiência (Erfarung) e a ocupação (Umgang) com as coisas mundanas são os pressupostos do processo instrutivo e dizem respeito ao horizonte de possibilidades de aprendizagem, que em contrapartida tem na instrução a ampliação do horizonte da experiência.

A formação do caráter tem seu horizonte formativo inscrito na ação e, importa destacar, que é no horizonte de ação que está o outro, e é isso que permite que se afirme que a formação moral, como ação, está inscrita em uma dimensão política. Sem a dimensão política não seria possível a formação moral e, nesse caso, a vontade seria reduzida a uma decisão sem escolha. $\mathrm{Ou}$ seja, tão somente uma "excitação sem determinação" uma ação cega a partir do desejo ou da ânsia. A vontade exige que se queira algo. Um querer que não torna o sujeito escravo de um objeto, mas que brote das "[...] emoções que se têm - consciente que se é senhor delas e com as esperanças que se atinja, mediante hábil combinação das mesmas, a finalidade em vista" (HERBART, 2010, p. 159). Segundo Benner (1997, p. 99), “[...] a ação é princípio a priori de formação do carácter, condicionado ao círculo de pensamentos".

O que resulta da formação do círculo de pensamentos é o que Herbart (1993) denomina de caráter, composto por uma parte objetiva e outra subjetiva. A parte objetiva corresponde ao círculo de pensamentos com as memórias da vontade. A parte objetiva constitui a estrutura mental que se apresenta ao sujeito como arcabouço teórico que embasa a ação deliberativa diante das situações de tomada de decisão. As memórias da vontade nunca estão acabadas e se mantêm em constante ampliação e aperfeiçoamento. Poderíamos dizer que a parte objetiva do caráter não é uma instância de decisão, mas é o que embasa as decisões. Benner (1993, p. 121) afirma que "[...] o caráter objetivo não determina a escolha, mas influencia o horizonte de possibilidades de escolha", à medida que o ator se insere em decisões em novos espaços de ação. Ora, a parte objetiva 
do caráter é o que se desenvolveu no sujeito ao se mover no mundo, ao aparecer para os outros e quando o mundo aparece para ele.

É nesse sentido que Andrea English (2013) retoma de modo muito interessante esses conceitos que nos ajudam a compreender o lugar dessa distinção que Herbart (1993) faz. Por caráter objetivo, de modo simples, podemos compreender aquilo que se estabilizou no caráter. $\mathrm{Ou}$ seja, como afirma o autor, quando o sujeito parte para as observações, parte para as mesas já com uma "[...] vontade e, por vezes, traços de caráter determinados" (HERBART, 1887, p. 90, tradução nossa).

O personagem "objetivo" diz respeito a todas as escolhas que uma pessoa fez até o presente momento em sua vida. Este lado do self é objetivo porque ele já é formado através de escolhas que, em grande medida, se tornaram hábitos e rotinas (ENGLISH, 2013, p. 8).

Mas Herbart (1887) sabe claramente que a objetividade do caráter, o círculo de pensamentos, não é suficiente para que esse possa ser caracterizado como moral. A dimensão ética reside na capacidade de se tomar em reflexão, de se converter e redobrar sobre si mesmo. Isso leva Herbart a deduzir que o sujeito possui uma parte subjetiva no caráter, um Selbst, e que é constantemente influenciado e perturbado, tanto pela parte objetiva do carácter e suas memórias de vontade, bem como pelo horizonte de ação no qual o sujeito constantemente se inscreve. "O 'caráter subjetivo' refere-se à autorreflexão, que julga o self objetivo, potencializando críticas, as escolhas e criando novas regras para a conduta futura" (ENGLISH, 2013, p. 8). E é nesse embate espiritual dialético que reside a dimensão da liberdade humana, em que o sujeito diante das perturbações, memórias de vontade, das novas situações, é colocado na esfera deliberativa e da liberdade humana. Essa é uma das ideias condutoras de sua filosofia prática que está na base de sua pedagogia - a ideia de liberdade interior. Não pode haver capacidade de moralidade, se o processo formativo não perseguir e fomentar o desenvolvimento da liberdade interior (HERBART, 1887, p. 355-357).

Apesar de Herbart conceber uma parte objetiva e outra subjetiva, não significa que compreenda a alma sob a perspectiva dualista. Pelo contrário, para o autor todos esses processos devem estar unificados e reunidos em uma consciência ou sob uma individualidade, um Selbst (HERBART, 1887, p. 91). Porém, essa alma se apresenta em esferas espirituais dialéticas e tensionadas em uma constante luta interior (inneren Kampf). Ou seja, quando os fundamentos apontados pela parte subjetiva estão em sintonia com as predisposições da parte objetiva, então segue-se a ação de modo contínuo e habitual. Quando as posições entre ambos estiverem em desacordo em relação a um horizonte de ação, se inicia a luta. A luta é o conflito pelo qual as disposições do caráter objetivo e o distanciamento próprio do caráter subjetivo apresentam-se divergentes e que, por um processo deliberativo, buscam a superação pelo ajuste de suas posições. E, nesse caso, ou se altera o habitual e a parte do objetivo com novas memórias, ou reafirma-se o que já está constituído, fortificando o que já se mostra acertado na condução do sujeito em um horizonte de ação. Benner (1993, p. 121) ressalta o aspecto da dialogicidade do processo, de tal modo que a parte subjetiva e objetiva do caráter se implicam reciprocamente, apontando alternativas para a tomada de decisão.

Segundo English (2013), a ruptura que se apresenta ao sujeito em relação ao seu caráter objetivo resulta em dilemas morais que são importantes e que, para Herbart, são o espaço que se abre ao sujeito para se ocupar consigo mesmo. As novas situações levam o caráter subjetivo a estar

${ }^{1}[\ldots]$ hat er einen Willen, und zuweilen sehr bestimmte Charakterzüge. 
de certo modo em desacordo consigo mesmo, configurando-se uma relação de tensão, de conflito consigo mesmo.

Quando experimentamos a luta interna, é porque nossas decisões passadas entram em conflito com as exigências da situação presente, portanto, nosso lado objetivo entra em conflito com nosso lado subjetivo. Luta interna marca o ponto em que nós podemos fazer alterações da maneira que agimos no mundo. $\mathrm{O}$ momento da luta interior, Herbart, observa, é um momento existencial tão vigoroso que ele pode ameaçar a saúde mental e corporal (ENGLISH, 2013, p. 8).

A memória da vontade é essencial, mas é preciso que o sujeito se exercite sobre ela. Porém esse exercício somente é possibilitado pela quebra que a disciplina (Zucht) causa sobre o hábito. Importante, ainda, é pensar que esse processo da parte subjetiva do caráter, que é a abertura potencializada pela parte objetiva, só é possível pela capacidade de o sujeito se observar, ou seja, de estar atento a si mesmo, de ouvir a voz da razão. Porém, é necessário, também, que esse caráter subjetivo se afaste do aspecto objetivo para se tomar em distância. Ou seja, se a parte objetiva é a parte estável, que se mostra necessária como uma parte estável e firme do caráter, por outro lado, a parte subjetiva é aberta ao mundo, inovadora, criativa e, nessa perspectiva, se coloca em conflito com a parte objetiva, provocando uma tensão pela qual se altera e renova a parte objetiva. Entretanto, ela é regulada pela tomada de decisão da parte objetiva. Eis o motivo de se necessitar de uma boa formação e constituição do círculo de pensamentos, sob o qual se sustentará o caráter objetivo, primordialmente.

Nessa direção, a educação não tem a possibilidade de interferir de modo direto sobre os processos pelos quais os sujeitos desenvolvem, para si, máximas de condução moral. Cabe à educação, tanto em relação aos fenômenos naturais como aos habituais,

[...] dar as indicações no sentido de conceder especial atenção às partes objetivas do carácter, e que, afinal, se vai erguendo e formando sob a sua vigilância e influência! Se ele estiver em ordem, então poderá esperar-se êxito e força orientadora de uma Ética, então o aspecto subjetivo terá ainda a realizar, é certo que conseguindo-o facilmente, a sensação, a última reificação e o aperfeiçoamento do caráter de formação moral (HERBART, 2010, p. 147).

Isso mostra, de alguma forma, o quanto é importante compreender que a formação moral e a formação de si são movimentos simultâneos de formação. Educação e instrução são processos que não deveriam ser dissociados. Para Herbart (1887, p. 10) não há educação que não ensine e ensino que não eduque. A educação interfere diretamente na formação do círculo de pensamentos a partir do qual se desenvolve o caráter moral. "Os limites de uma ideologia são os limites para o caráter, porque nem de longe toda a ideologia passa à ação" (HERBART, 1887, p. 100). É na relação dialética entre o conhecimento (Gedangenkreis) e a reflexão (Besinung), na ação de se distanciar do habitual e tomar-se em reflexão, que o homem se torna capaz de moralidade.

Nessa tensão ou luta interior há um outro ponto importante a ser considerado. Trata-se de compreender como se desencadeia o movimento pelo qual o sujeito se toma em reflexão e fortalece seu caráter moral. Para tanto, poderíamos lançar a pergunta: o que desencadeia ou provoca a luta interior ou faz o sujeito se voltar sobre si mesmo? O que faz com que se distancie ou suspenda seu juízo habitual?

Para responder tais indagações é imprescindível trazer à luz o conceito de disciplina formativa (Zucht) ou aconselhamento (Beratung) como preferem English (2013) e Benner (1993). A contribuição da disciplina para a formação (Bildung) não se refere tanto à educação escolar, mas à 
educação de modo geral. Nesse sentido, manter a ordem e a organização na sala de aula, evitar a distração em relação ao professor, são coisas do governo. A disciplina se dá em outra ordem e pretende ser um momento de censura e, nesse sentido, provocar a suspensão temporária do juízo habitual. Nessa suspensão há um momento de abertura fundamental do sujeito a si mesmo, que torna possível o processo de ampliação e constituição de si. E, desse modo, a ação da disciplina pretende ser parte integrante da formação, no sentido mais profundo de Bildung. Essa exige a presença do outro no espaço educativo, do mestre que, no dizer franco e aberto, se posiciona com sinceridade e precisa do retorno sincero do educando.

Essa abertura é o que English (2013, p. 9) denomina de discontinuity in learning e representa um momento importante para a aprendizagem moral. "Esta forma de descontinuidade é significativa para a compreensão da ideia de educação em direção à autodeterminação: a luta marca o ponto em que há uma abertura na experiência do indivíduo, um espaço em que ela tem a escolha de romper com escolhas passadas e agir diferentemente no futuro".

A disciplina formativa $(Z u c h t)$ assume, aqui, enquanto ação pedagógica, o papel de fortalecer o caráter, fortificando as memórias da vontade sob duas perspectivas: primeiramente para que as memórias que constituem a parte objetiva do caráter ganhem em força e operem nas tomadas de decisão do sujeito; em segundo lugar, em virtude de sua força, levam à tensão, ou a uma situação de conflito diante de novas situações que se apresentam, não para se imporem incondicionalmente, mas para provocar a reflexão pela luta interior. E é desse lugar que se orientará a decisão e a vontade como ação. Em relação a isso, é importante observar como Herbart se preocupa em manter a abertura do espaço da tomada de decisão, com o devido cuidado para compreender o que é fundamental em sua proposta de pedagogia, que é a liberdade interior do sujeito e, consequentemente, a pretensão de autogoverno. O que Herbart pretende destacar é a relação entre "[...] persistência das nossas representações e a persistência da vontade" (ENGLISH, 2013, p. 8) que para ele é essencial e tem profundas implicações para a decisão moral.

\section{AS TRÊS FIGURAS DE SÓCRATES}

Nesse processo de constituição de si como sujeito capaz de moralidade, torna-se fundamental a capacidade de pensar. Esta passa pelo processo de suspensão do mundo, um recuar espiritual, que permite que o sujeito se tome em reflexão. A questão que se põe, então, é qual a implicação desse processo para a educação e para os processos formativos? Entre as muitas questões e exigências que possam acarretar para a educação, cabe aqui destacar o papel do mestre. Arendt (2007) propõe procurar um modelo, um exemplo que, ao contrário dos pensadores profissionais, poderia ser representativo e que, para a autora, só poderia ser Sócrates. Nessa direção, Arendt (2007) destaca três figuras metafóricas de Sócrates: o do moscato (inseto que sabe ferroar os cidadãos para despertar os mesmos); da parteira (que conhece a técnica de partejar e trazer à luz ideias e que, em si mesmo, é estéril); e da arraia-elétrica (que com o seu choque causa paralisia em relação aos negócios humanos, choque este que é a perplexidade). Nestas três figuras é possível encontrar indicativos para responder a questão sobre o que nos faz pensar e sobre o papel da ação pedagógica.

A partir dessas três figuras, Arendt (2014, p. 195) quer primeiramente mostrar, através de Sócrates, que a filosofia, o processo que faz pensar é próprio de quem não é sábio, mas que se encontra em uma "[...] busca que o mantém tão ocupado que sequer deixa tempo para os negócios públicos ou privados". E nesse sentido, a autora salienta que, em Sócrates, não encontramos um único modo de pensar, mas muitas variantes como resposta à pergunta - o que nos faz pensar? "[...] Sócrates é essa figura que se move para além do lugar em que nos encontramos, uma vez que 
leva a sacudir os pensamentos-palavras (conceitos, frases, definições, doutrinas), retirando o sujeito de seu sono profundo, deixando o mesmo desperto e vivo" (ARENDT, 2014, p. 197). O mestre é aquele que provoca o pensamento, um momento de "interrupção de todas as atividades" podendo ser o sujeito atordoante e, "[...] depois que o deixamos, nos sentindo inseguros sobre o que parecia acima de qualquer dúvida enquanto estávamos impensadamente engajados em fazer alguma coisa" (ARENDT, 2014, p. 197). Importante aqui é pensar que o pensamento é um dois-em-um, uma atividade que se apresenta como um diálogo interior em que a vida cotidiana é sempre interrompida pelo pensamento. A continuidade ordinária das coisas é suspensa e nos leva a um momento de distanciamento do passado, do nosso selbst, e nos permite pensar sobre ele, para orientar o futuro ao mirar o horizonte.

São os estudos de Arendt (2007) sobre Santo Agostinho que apresentam uma posição sobre as relações entre "estar no mundo" (agir) e o "afastar-se do mundo" (pensar). Desse modo, podemos considerar que a pluralidade não é abolida pela solidão do pensamento, do diálogo consigo mesmo, mas que ela pode aparecer para si próprio. Além disso, para Sócrates, "[...] o critério decisivo do homem que diz com verdade a sua própria doxa é 'que esteja de acordo consigo mesmo' que não se contradiga a si próprio e não diga coisas contraditórias [....]" (ARENDT, 2007, p. 22). Esse medo da contradição "[...] resulta do facto de cada um de nós 'que [é] um só', poder ao mesmo tempo falar consigo próprio [...], como se fosse dois”. E o fato de ser dois-num-só, pelo menos quando tento pensar, faz com que eu possa fazer a experiência de um amigo como um outro si-próprio, diz Arendt (2007), citando Aristóteles. Só aquele que tem a experiência de falar consigo próprio será capaz de ser um amigo, de adquirir um outro si-próprio.

Nesse contexto, conforme Arendt (2007), Sócrates estava convencido de que ninguém poderia querer viver com um assassino ou num mundo de assassinos potenciais. Aquele que sustenta que um homem pode ser feliz sendo um assassino, contanto que ninguém disso tenha conhecimento, está em duplo desacordo consigo mesmo, pois apresenta uma afirmação autocontraditória e mostra-se como querendo viver com alguém que não pode aprovar. Este duplo desacordo era, para Sócrates, um só e mesmo fenômeno. Tal é a razão por que pensa que a virtude pode ser ensinada, ou, para o dizermos de um modo menos trivial, é a consciência de que o homem é um ser pensante e agente em um ser só, o que torna melhores os homens e os cidadãos (ARENDT, 2007); consequentemente, responder ao mundo significa estar disposto a responder e prestar contas a nós mesmos.

O que Sócrates queria, segundo Arendt (2007), era sempre permanecer um homem entre outros homens, sem nunca evitar a praça pública, ser um cidadão entre cidadãos, reivindicando algo que qualquer outro cidadão pode e deve reivindicar. A partir disso, fez com que cada um fosse participante da vida pública, da atividade de pensar. Em suma, ele queria era ter o "[...] direito de examinar as opiniões alheias, pensar sobre elas e pedir a seus interlocutores que fizessem o mesmo" (ARENDT, 2014, p. 126-127). Tem-se, desse modo, um pensamento político por excelência, de alguém disposto a partilhar e compreender o mundo a partir do ponto de vista do outro, dialogando sobre o que nos é comum, que está entre-nós, de tal modo que este entre-nós represente a constituição de um mundo comum, na possibilidade de podermos viver juntos.

\section{CONSIDERAÇÕES FINAIS}

O presente texto procurou mostrar como é possível aproximar a filosofia de Hannah Arendt (1996, 2004, 2007, 2010, 2014) e Johann Friedrich Herbart (1887, 1976, 2010), no que toca a questão da suspensão do fluxo mudando e habitual, como ação que impulsiona o sujeito a se tomar em distância e, portanto, pensar. Trata-se da ação de suspensão e censura do mundo como 
momento privilegiado de abertura a si mesmo e de distanciamento do habitual como estímulo reflexivo e, nesse sentido, como momento de formação ética e política. É o momento em que o sujeito se toma de reflexão permitindo reformular e lapidar sua capacidade de moralidade. É o instante do pensamento, em que o sujeito se encontra desprendido do mundo sem sair dele, mas em reflexão consigo mesmo, podendo se reconstituir ou até mesmo reafirmar.

Se a atividade de pensar resulta e está inscrita na atividade de conhecer, paradoxalmente como ruptura, e sua consequente abertura especulativa e criativa em relação ao mundo, este momento também se apresenta como caminho para constituição da capacidade de moralidade de um sujeito. Essa capacidade está sustentada e tem por base a constituição de um círculo de pensamentos, de um interesse múltiplo e ampliado que se orienta em múltiplas direções e horizontes, e constituído a partir do aparecimento do homem no mundo das aparências. É no encontro com o mundo e com os outros iguais a si que o homem constitui esse repositório de saberes, que potencializa sua capacidade de deliberação moral. Portanto, é na esfera da ação humana, do encontro com o outro, que o ser humano tem a possibilidade de se aperfeiçoar moralmente. É no outro que encontra a si mesmo e lhe é possível se tomar em reflexão realizando o aperfeiçoamento e o desenvolvimento de si. Significa que, em Hannah Arendt (1996, 2004, 2007, 2010, 2014), assim como em Herbart (1887, 1976, 2010), o processo de desenvolvimento da capacidade de moralidade está intrinsecamente ligado e imbricado com a esfera política e estética do ser humano.

E, por fim, é importante destacar que, no processo de amadurecimento moral do sujeito, o mestre tem papel fundamental, papel muitas vezes desconstruído e relativizado nas teorias pedagógicas contemporâneas. O mestre é aquele que, além de despertar, desafiar ao partejo de ideias, causa a descontinuidade pela paralisia. Nas palavras de Arendt (2014), a suspensão do mundo é o recuo espiritual; na concepção de Herbart (1887), a descontinuidade pelo aconselhamento da disciplina formativa, libertando o sujeito e provocando abertura deste, a si mesmo. Em síntese, significa que o mestre assume o papel de provocar a reflexão e o pensamento proporcionando, ao pensamento, acontecer.

\section{REFERÊNCIAS}

ALMEIDA, Vanessa S. de. Educação em Hannah Arendt. entre o mundo deserto e o amor. São Paulo: Cortez, 2011.

ARENDT, Hannah. A vida do espirito: o pensar, o querer, o julgar. Tradução César Augusto R. De Almeida; Antônio Abranches; Helena Franco Martins. Rio de Janeiro: Civilização Brasileira, 2014. ARENDT, Hannah. A condição bumana. Tradução: Roberto Raposo. Revisão técnica: Adriano Correia. Rio de Janeiro: Forense Universitária, 2010.

ARENDT, Hannah. A promessa da politica. Trad. de Miguel Serras Pereira. Lisboa: Relógio D’ Água Editores, 2007.

ARENDT, Hannah. O que é política? Trad. de Reinaldo Guarany. 5. ed. Rio de Janeiro: Bertrand Brasil, 2004.

ARENDT, Hannah. Die Krise in der Erziehung. Zwischen Vergangenheit und Zukunft: Übungen im politischen Denken 1. München: Piper, 1996. p. 255-276.

BENNER, Dietrich. Die Pädagogik Herbarts: Eine problemgeschichtliche Einfürung in die Systematik neuzeitlicher Pädagogik. Weinheim: Juventa, 1993.

BENNER, Dietrich. Johann Friedrich Herbart Systematische Padagogik: interpretationen (Band 2). Weinheim: Deutscher Studien Verlag, 1997. 
DAMÁSIO, Antônio. E o cérebro criou o homem. Tradução Laura Teixeira Motta. São Paulo: Companhia das Letras, 2011.

ENGLISH, Andrea R. Discontinuity in Learning: Dewey, Herbart, and Education as Transformation. Cambridge: Cambridge University Press, 2013.

HERBART, Johann Friedrich. Allgemeiner Pädagogik aus der Zweck der Erziehung Abgeleitet. In: KEHRBACH, Karl; FLÜGE, Otto; FRITZSCH, Theodor (orgs.). Johann Friedrich Herbart's sämtliche Werke in chronologische Reihenfolge. Langensalza: Hermann Beyer \& Söhne, 1887. 2 v. p. 1136.

HERBART, Johann Friedrich. Pedagogia geral: deduzida da finalidade da educação. Tradução Ludwig Scheidl. Lisboa: Fundação Calouste Gulbenkian, 2010.

HERBART, Johann Friedrich. Vorlesung über Pädagogik (1802). In: HOFMANN, Franz; EBERT, Berthold (orgs.). Ausgewählte Schriften zur Pädagogik. Berlin: Volk und Wissen Volkseigener Verlag, 1976. p. 383-393.

KANT, Immanuel. Crítica da razão pura. Tradução de Manuela Pinto dos Santos e Alexandre Fradique Morujão 5. ed. Lisboa: Fundação Calouste Gulbenkian, 2001. (Coleção: Textos clássicos). NETO, Rodrigo Ribeiro Alves. O Sócrates de Hannah Arendt. Natal, Rio Grande do Norte: UFRN, 2009. Disponível em: http://www.cchla.ufrn.br/humanidades2009/Anais/GT04/4.2.pdf. Acesso em: 21 out. 2018.

Submetido em novembro de 2019 Aprovado em fevereiro de 2020

\section{Informações dos autores}

Jenerton Arlan Schütz

Universidade Regional do Noroeste do Estado do Rio Grande do Sul (UNIJUI)

E-mail: jenerton.xitz@hotmail.com

ORCID: https://orcid.org/0000-0002-3603-7097

Link Lattes: http://lattes.cnpq.br/6075418179655079

Odair Neitzel

Universidade Federal da Fronteira Sul (UFFS)

E-mail: odair.neitzel@uffs.edu.br

ORCID: https://orcid.org/0000-0001-8121-1149

Link. Lattes: http://lattes.cnpq.br/0750444554945581 